\title{
Effect of genetic and environmental factors on the growth performance traits of Pak-Awassi sheep
}

\author{
Asif Raza, Hubdar Ali Kaleri, Rameez Raja Kaleri*, Asma Kaleri, \\ Muhamad Bux, Mushtaque Ahmed Jalbani, Ali Ghulam, Depeesh \\ Kumar and Abdul Karim \\ Department of Animal Breeding and Genetics, Sindh Agriculture University, Tandojam-Pakistan \\ *Corresponding author's email: rameezkaleri@gmail.com
}

Citation

Asif Raza, Hubdar Ali Kaleri, Rameez Raja Kaleri, Asma Kaleri, Muhamad Bux, Mushtaque Ahmed Jalbani, Depeesh Kumar and Abdul Karim. Effect of genetic and environmental factors on growth traits of Pak-Awassi sheep. Pure and Applied Biology. Vol. 6, Issue 2, pp532-537. http://dx.doi.org/10.19045/bspab.2017.60054

\begin{tabular}{llll}
\hline \hline Received: 30/01/2017 & Revised: 29/03/2017 & Accepted: 02/04/2017 & Online First: 04/04/2017 \\
\hline \hline
\end{tabular}

\section{Abstract}

Present research was carried out to investigate the genetic characteristics of Pak-Awassi Sheep with respect to the growth performance traits and estimation of the genetic parameters. The 10 years (2004-2013) data regarding the growth performance traits of Pak-Awassi sheep maintained at livestock experimental station Nabisr, Umar Kot, Sindh were utilized for the current study. The result for genetic parameters heritability for birth weight and yearling weight was observed low, while correlation and regression coefficient was observed medium and positive for birth weight and yearling weight. The effect of season was observed significantly higher on lambing rate of Pak-Awasi sheep. It is concluded that winter season has significant effect on lambing rate, while the low heritable traits can be improved with better management and selection practices.

Keywords: Pak-Awassi; Genetic parameter; Heritability; Correlation; Regression coefficient

\section{Introduction}

At present Pakistan has 28 sheep breeds and Sindh possess about $16 \%$ to total sheep population of Pakistan [1]. Small ruminant especially sheep is well known for serving multipurpose animals for milk, meat and wool. Pak-Awassi sheep breed is cross of Awassi sheep of Lebanon and Kachhi native breed of Sindh, that is why this breed is well known for serving multipurpose sheep for milk, meat and wool purpose. Pak-Awassi sheep commonly found in Tharparkar district of Sindh. Information regarding the genetic factors and their influence on the productive traits is of interest to farmers as well as the animal breeders, because influence of genetic factors helps to improve animal production and also in the planning of herd management program [2, $3]$. The concept of genetic parameters such as heritability, correlation and regression estimates are essential for planning of efficient breeding programs and to predict the response to selection, high values of genetic factor can cause improvement of productive traits of selected animals $[3,4]$.

\section{Material and methods}

The available Ram-wise data of 10 Ram's with total 14 animals of each Ram of PakAwassi sheep was brought under the study. The data regarding growth traits including birth weight and yearling weight was maintained and collected for period of 10 years 2014 to 2013 on especially designed profroma. The data was collected from 
livestock experimental station Nabisr, Umar Kot, Sindh, Pakistan.

\section{Genetic analysis}

The estimation of genetic parameters heritability, correlation and regression coefficient was analysed according the formula as suggested by (Becker, 1985) [3].

\section{Season of lambing}

The seasons of lambing were divided into two seasons, i.e. summer (April - to September) and winter (October- March).

\section{Results}

The Ram-wise data for birth weight and yearling weight of Pak-Awassi sheep The Ram-wise results for birth was observed higher in Ram-Tag: 2 $\left(3.742 \pm 0.148^{\mathrm{ab}}\right)$, while it was observe lower in Ram-Tag: 17 (3.601 $\left.\pm 0.145^{\mathbf{d}}\right)$. The Ram-wise results for yearling weight was found in Ram-Tag: 18 (38.264 $\left.\pm 1.540^{\mathrm{a}}\right)$, whereas it was observed lower in RamTag: $3 \quad\left(37.027 \pm 2.519^{\text {abc }}\right)$ details are mentioned in Table 1.

Tabel 1. Ram-wise average birth weight and yearling weight

\begin{tabular}{|l|l|l|l|}
\hline S: No & Ram's Tag No. & Birth Weight $(\mathrm{kg})+$, SD & Yearling Weight $(\mathrm{kg})+,S D$ \\
\hline 1 & 01 & $3.625 \pm 0.123 \mathrm{~b}^{\mathbf{c d}}$ & $37.811 \pm 3.171^{\mathbf{a}}$ \\
\hline 2 & 02 & $3.742 \pm 0.148^{\mathbf{a b}}$ & $37.436 \pm 2.088^{\mathbf{a b c}}$ \\
\hline 3 & 03 & $3.618 \pm 0.148^{\mathbf{c d}}$ & $37.027 \pm 2.519^{\mathbf{a b c}}$ \\
\hline 4 & 04 & $3.636 \pm 0.182^{\mathbf{b c d}}$ & $37.826 \pm 2.117^{\mathbf{a}}$ \\
\hline 5 & 05 & $3.702 \pm 0.201^{\text {abcd }}$ & $36.116 \pm 1.311^{\mathbf{c}}$ \\
\hline 6 & 07 & $3.731 \pm 0.187^{\mathbf{a b c}}$ & $36.830 \pm 1.042^{\mathbf{a b c}}$ \\
\hline 7 & 12 & $3.643 \pm 0.169^{\mathbf{b c d}}$ & $37.656 \pm 2.003^{\mathbf{a b}}$ \\
\hline 8 & 13 & $3.639 \pm 0.112^{\mathbf{b c d}}$ & $37.475 \pm 1.464^{\text {abc }}$ \\
\hline 9 & 17 & $3.601 \pm 0.145^{\mathbf{d}}$ & $36.195 \pm 1.343^{\mathbf{b c}}$ \\
\hline 10 & 18 & $3.763 \pm 0.167^{\mathbf{a}}$ & $38.264 \pm 1.540^{\mathbf{a}}$ \\
\hline
\end{tabular}

Means bearing different superscript indicates significant difference LSD $=(\mathrm{P}<0.05)$

Results of heritability $\left(\mathrm{h}^{2}\right)$ and correlation coefficient estimates for birth weight and yearling weight

The results of heritability $\left(\mathrm{h}^{2}\right)$ estimates for birth weight and yearling weight of Pak-
Awassi sheep was observed low. While the correlation coefficient estimates was observed positively high among birth weight and weaning weight, details are given in Table 2.

Table 2. Results of heritability $\left(\mathrm{h}^{2}\right)$ estimates for birth weight and yearling weight

\begin{tabular}{|l|l|l|}
\hline Breed & Traits & Heritability $\left(\mathrm{H}^{2}\right)$ \\
\hline \multirow{3}{*}{ Pak-Awassi } & Birth Weight $(\mathrm{kg})$ & 0.235 \\
\cline { 2 - 3 } Breed & Yearling weight $(\mathrm{kg})$ & 0.227 \\
\hline Pak-Awassi & Traits & Correlation coefficient \\
\hline
\end{tabular}

\section{Results of regression coefficient estimates between birth weight and yearling weight}

The results of regression coefficient estimates are presented in graph. The graph shows a positive and strong relationship between both traits of PakAwassi sheep, details are present in Graph 1. 


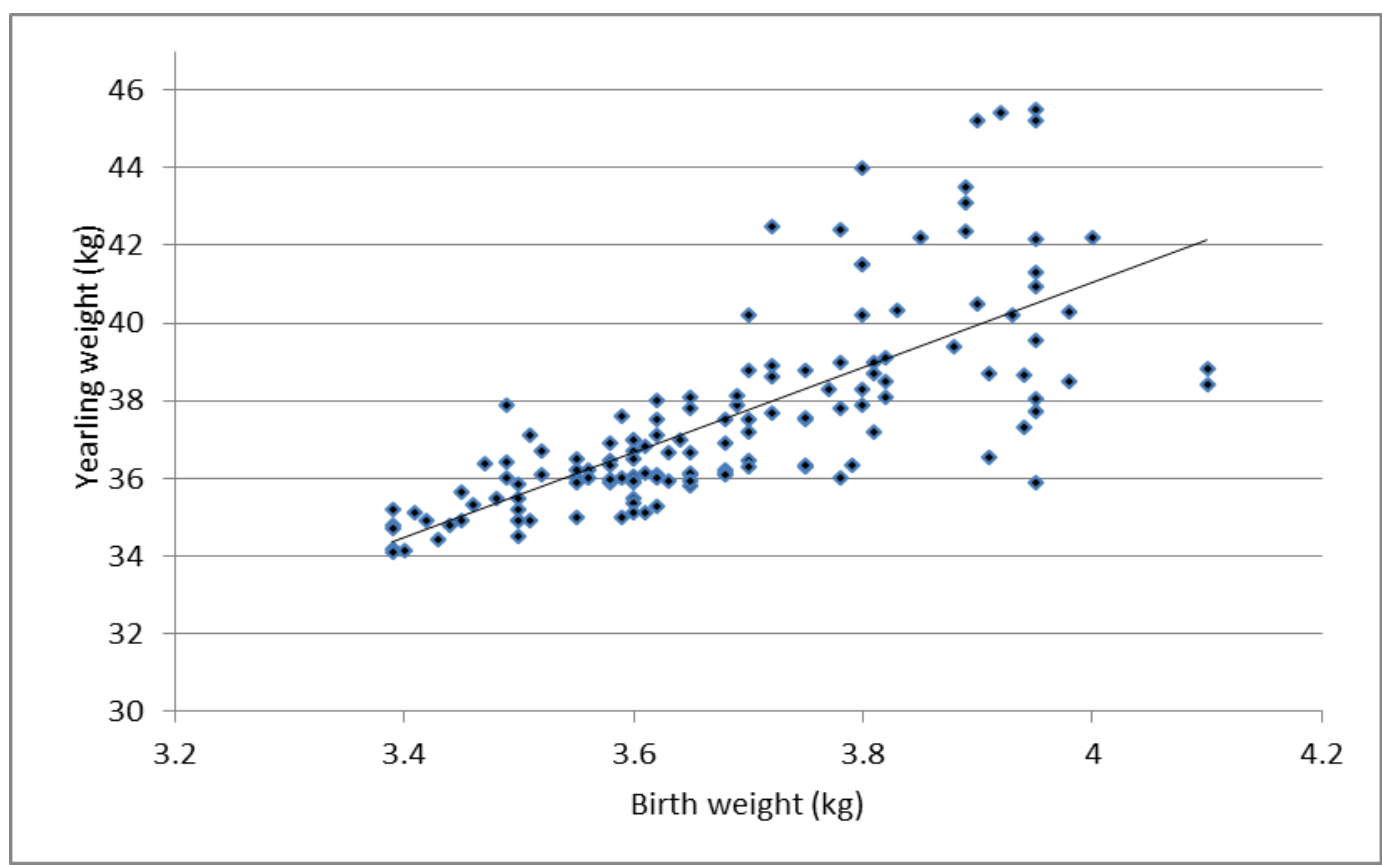

Graph 1. Results for regression coefficient estimates between birth weight and weaning weight

The results for the effect of season on the lambing rate of Pak-A wassi sheep The season wise lambing results of PakAwassi sheep showed that higher lambing rate was observed in winter season
(October to March), while lower lambing rate was found in summer season (April to September), details are presented in Table 3.

Tabel 3. Season-wise lambing of Kachhi and Pak-Awassi sheep breeds

\begin{tabular}{|l|l|l|l|l|}
\hline Breeds & \multicolumn{1}{|c|}{ Season } & No of Birth & Percentage & $\begin{array}{l}\text { No of Total } \\
\text { births }\end{array}$ \\
\hline \multirow{2}{*}{ Pak-Awassi } & Winter (October to March ) & 98 & $77 \%$ & \multirow{2}{*}{140} \\
\cline { 2 - 4 } & Summer (April to September) & 42 & $30 \%$ & \\
\hline
\end{tabular}

Effect of season of lambing on birth and yearling weight of Pak-A wassi sheep The lambs which were born during the season of winter ( October to March ) their birth weight and yearling weight was observed higher as compared to those lambs which were born during season of summer (September to April ), details are presented in Tabel 4.

Tabel 4. Results for effect of season of lambing on the birth weight and yearling weight

\begin{tabular}{|l|l|l|l|}
\hline Season of lambing & $\begin{array}{l}\text { No. of } \\
\text { observation }\end{array}$ & $\begin{array}{l}\text { Birth weight } \\
\text { Mean+ S.E }\end{array}$ & $\begin{array}{l}\text { Yearling weight } \\
\text { Mean+S.E }\end{array}$ \\
\hline Winter (October to March) & 98 & $3.750 \pm 0.013^{\mathbf{a}}$ & $381.372 \pm 0.223^{\mathbf{a}}$ \\
\hline Summer (April to September) & 42 & $3.528 \pm 0.021^{\mathbf{b}}$ & $35.678 \pm 0.341^{\mathbf{b}}$ \\
\hline
\end{tabular}

Means bearing different superscript indicates significant difference LSD $=(\mathrm{P}<0.05)$ 


\section{Discussion \\ Ram-wise birth weight and yearling weight}

The results of current showed that higher birth weight was observed in Ram 2 and 18, while birth weight and yearling weight was observed lower in 17 and 3 respectively. The findings of current study are in agreement with the results of $[5,6]$, who reported ram has significantly effect on the birth weight and yearling weight of Hissardali and Dumbi sheep breeds. The results of current investigation in controversial by the research of [7], who observed non -significant effect on birth weight and yearling weight of Mecheri sheep. The different among the studies may be due to different environmental conditions and management pattern as well number of ram and present of accurate data regarding the dam and its offspring.

\section{Heritability and correlation and} regression coefficient

In current investigation the results of heritability was observed lower as compared to study conducted by $[8,9]$, who reported high heritability estimates for birth weight and yearling weight Kachhi and Pak-Awassi sheep breed respectively. The same statement repeated by $[10,11]$, they had also mentioned high heritability for birth weight and yearling weight in Suffolk and Karadi sheep breeds. The results of correlation and regression coefficient showed positive and high correlation and regression coefficient between birth weight and yearling weight of Pak-Awassi sheep. The findings of our study are in agreement with the research conducted by of [11-13], they had been reported higher as well as positive correlation and regression coefficient between birth weight and yearling weight of Awassi, Karadi and indigenous Ethiopian Horro sheep breeds. The same results also observed by $[6,7]$, they have also reported high and positive correlation as well as regression coefficient between birth weight and weaning weight of Turkish Awassi and cross breed sheep. The findings of our study are opposition to the results of [14] in Barki and [15], they reported lower correlation and regression coefficient between birth weight and yearling. The mention difference may because of different seasons and different feeding process and availability of fodder. Low observation of correlation and regression may be due to inbreeding depression, while high positive correlation as well as regression estimates showed increase in one traits will positively affect or increase other trait.

\section{Effect of season on lambing rate and birth weight and yearling weight}

The effect of season on lambing rate as well as on the birth weight and yearling weight in current study was found significant. The observation of current results are in opposition of results of [16, 17], they reported that season was observed nonsignificant effect of season lambing rate, birth weight and yearling weight of Baluchi sheep breed in Baluchistan. The different among study may be due to dry arid land and climatic conditions and their effect of Baluchistan province. The findings of current study are in agreement with the results of $[6,18]$, they had reported higher significant effect of season on lambing rate and birth weight and yearling weight of Madras red sheep breed. The similar statement reported by $[3,19]$ they reported higher lambing rate in winter and lower in summer season, while birth weight and yearling weight was also observed higher in winter as compared lower in summer season. The different among researchers is due difference of breed their genetic diversity and climatic condition such as hot, humid and cold season has greater effect on the lambing rate and growth traits of animals. 


\section{Conclusion}

It was concluded the genetic and nongenetic parameter has greater effect on the growth traits of Pak-Awassi sheep. Due to low heritability results it is concluded to improve low heritable traits with the help of management and feeding practices of farm due to better management and feeding effect of non-genetic factors can also be overcome.

\section{Authors' contributions}

Conceived and designed the experiments: HA Kaleri \& RR Kaleri, Performed the experiments: M Asif, A Kaleri, D Kumar \& MA Jalbani, Analyzed the data: HA Kaleri. Contributed reagents/ analysis/ tools: A Karim \& AG Bugti, Wrote the paper: HA Kaleri \& RR Kaleri.

\section{References}

1. Bugti A, Kaleri HA, Kaleri RR, Jalbani MA \& Faisal A (2016). Correlation and regression coefficient estimates of Baluchi sheep breed. J Appl Environ Biol Sci 6(11): 28-35.

2. Bagheri M, Shahrbabak MM \& Torshizi RV (2006). Genetic and phenotypic correlation of composite taists with birth and weaning weight in Baluchi sheep. Proceedings of the 8th World congress on Genetics Applied to Livestock Production, Belo horizonte Minas Gerais Brazil 04-12.

3. Becker WA (1985). Manual of procedures in quantitative genetics, 4th edition, Academic enterprises Washington State University, Pullman Washington 62.

4. Akhtar P, Ahmad Z, Mohiuddin G, Ali S \& Javed K (2001). Environmental factors affecting preweaning growth traits of Hissardale sheep in Pakistan. Pak Vet J 21(1): 17-21.

5. Thiruvenkadan AK, Chinnamani K J, Muralidharan \& Karunanithi K (2008). Effect of non-genetic factors on birth weight of Mecheri sheep of India.
Livestock Research for Rural Development 20 (6): 2008.

6. Nawaz, M. Ahmad MD, Ahmad Z, Khan GR \& Khan MA (1985). Comparative performance of Awassi, Kachhi and crossbred (Kachhi x Awassi) lambs. Pakistan J Agri Sci 22(3): 181-187.

7. Mushtaq HL \& Tasawar Z (2010). Genetic potentials of local breed of sheep habituating around Dera Ghazi Khan, Pakistan. Sarhad J Agric 26: 205-207

8. Hafez E \& Saeed E (1962). Reproduction in Farm Animals. (2nd edition). Lea and

Febizer,

Philadelphia.

9. Juma KH, Alkass JE, Amir A \& Fahim T (1998). Factors affecting on yearling

weight in indigenous Iraqi sheep. Proc. $6^{\text {ttl }}$ World Cong., Genetics Applied to Livestock, Armidale, Australia 11-16 January 24: 220-222.

10. Gürsoy O (2005). Small ruminant breeds of Turkey. In Characterization of Small Ruminant Breeds in West Asia, North Africa, Vol 1: West Asia, Luis Iñiguez, $\quad$ Ed. ICARDA Aleppo Syria 239-416.

11. Abegaz S, Duguma G, Gelmesa F Terefe E, Negussie \& Rege JE (2002). Non-genetic factors affecting early growth traits and survival in Horro sheep. Tropical Agric 79 (3): 154160.

12. Mahmoud A (2000). Heritability, genetic and phenotypic correlations of pre-weaning

growth traits of Rahmany and Barki lambs. Alexandria J Agric Res 45(1): 214-218.

13. Ebangi AL, Njoya A, Ngo-Tama AC, Awa DN \& Mbah DA (2001). Genetic and phenotypic parameters of birth weight traits in Fulbe sheep in Cameroon. Revue. d' Elevage et de 
Medecine Veterinaire des Pays

14. Sivakumar T, Soundararajan C, Palanidorai R, Ganeshkumar K, Mahendran M \& Malathi G (2006). Factors affecting on birth weight in Madras Red lambs. Indian Journal of Small Ruminants 12: 115-116.

15. Yazdi MH, Engstem G, Nasholm A, Johansson K, Jorijani H \& Liljedahi LE (1997). Genetic parameters of lamb weight at different ages and wool production in Baluchi sheep. $J$ Anim Sci (65): 247-55.

16. Sarwar M, Khan MA, Nisa M \& Iqbal $Z$ (2002). Dairy industry in Pakistan: A Scenario. Int J agric Biol 4: 420428.

17. Refik A, Ceyhan, Ozder O \& Sezenler T (2009). Genetic and Non-Genetic
Tropicaux 54(2): 147- 151.

Parameter Estimates for Growth Traits in Turkish Merino Lambs. Journal of Animal and Veterinary Advances 8(9): Page No. 1729-1734.

18. Eskandarinasab M, Ghafouri-Kesbi F, \& Abbasi MA (2010). Different models for evaluation of growth traits and Kleiber ratio in an experimental flock of Iranian fat-tailed Afshari sheep. Journal of Animal Breeding and Genetics Volume 127; 26-33(8).

19. Garcia FX, Mansilla MA \& Garcia DG (1980). Effect of some environmental factors on sheep production. Advances en Produccion Animal. 5(1): 3-13. (Anim. Breed Abst 56: 3765, 1986). 